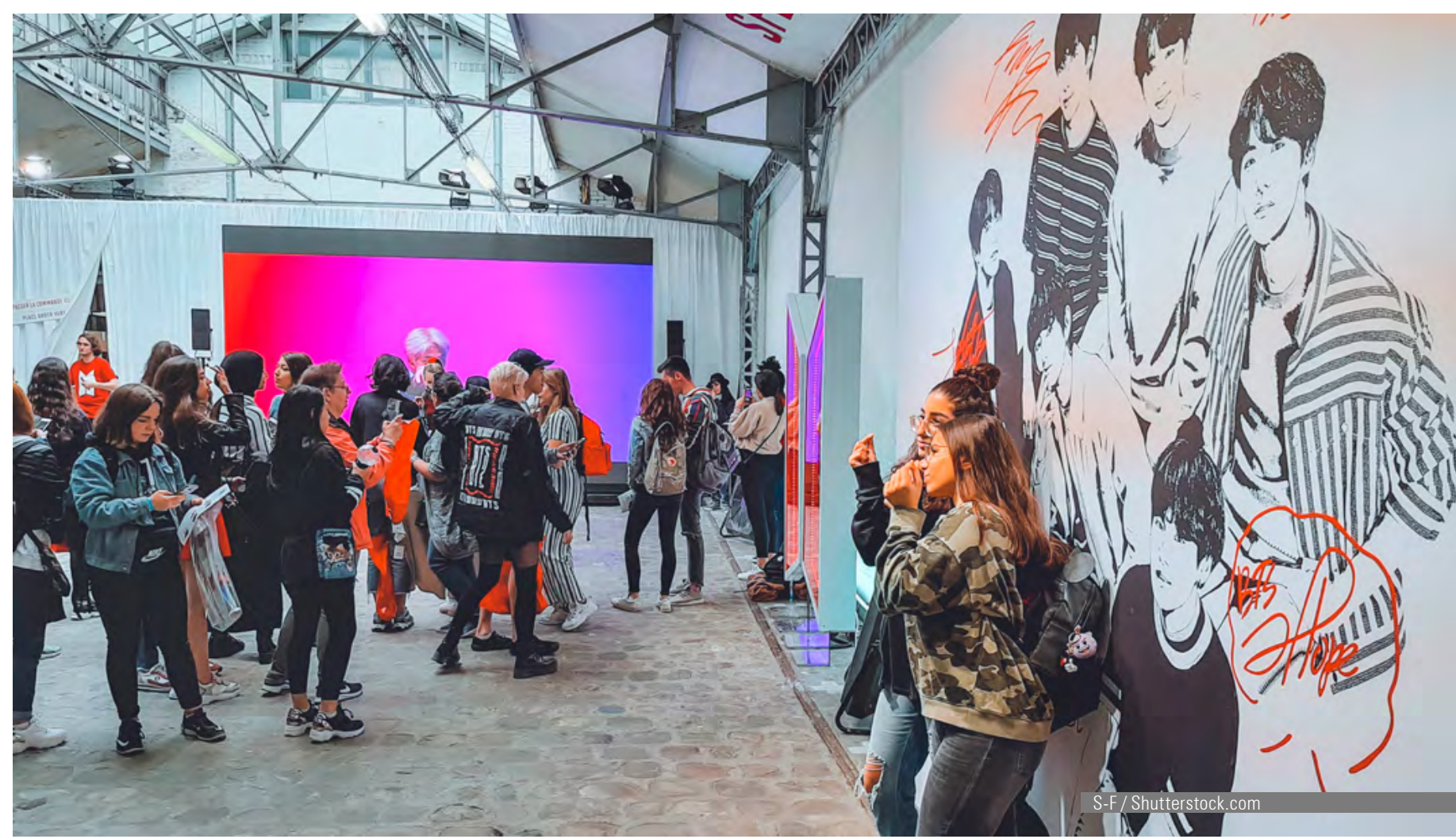

\title{
La Ola Coreana en México. Redes sociodigitales y fangagement
}

\section{The Korean Wave in Mexico. \\ Sociodigital Networks and Fangagement}

>> Rodrigo Alpízar Jiménez

Universidad Autónoma Metropolitana ro.aj1988@hotmail.com

\section{Adriana Robledo Sánchez}

Universidad Autónoma de Querétaro adriana.rs05@outlook.com

Recibido: 19 de febrero 2021.

Aprobado: 20 de abril 2021.

Publicado: 30 de junio 2021.

\begin{abstract}
Resumen
Esta propuesta parte del supuesto de concebir a la Ola Coreana como una industria capaz de producir, comercializar y comunicar manifestaciones culturales de forma masiva gracias a la incorporación de los nuevos recursos tecnológicos y digitales empleados para difundir mensajes a mayor escala. Este hecho ha permitido la presencia de diversos productos culturales coreanos derivados del Hallyu en distintos lugares del mundo, como es el caso de algunos países latinoamericanos y, en especial, de México. Las ideas aquí presentadas son producto de una extensa revisión bibliográfica, parte de un proyecto de investigación de posgrado cuyo objetivo central está enfocado en analizar las prácticas de consumo por parte de las personas mexicanas que se asumen como fans de esta industria. Como se verá a lo largo de esta propuesta, son los fans organizados los que han desempeñado un papel de suma relevancia para la expansión y el consumo de las distintas manifestaciones culturales del Hallyu. Así pues, una gran parte de la información que compone este texto se desprende del estado del arte examinado para la construcción del proyecto antes señalado, así como de una serie de ejem-
\end{abstract}


plos empíricos que han tenido lugar, sobre todo en el contexto mexicano, los cuales permiten observar las interacciones cercanas entre las celebridades coreanas y sus fanáticos, gracias al uso y sentido que se les ha atribuido a las redes sociodigitales en la actualidad.

\section{Palabras clave}

Ola Coreana; Industria cultural; Industria creativa; Fangagement; Redes sociodigitales, K-pop, K-drama.

\section{Abstract}

This proposal is based on the assumption of conceiving the Korean Wave as a cultural industry capable of massively producing, commercializing, and communicating cultural manifestations by incorporating new technological and digital resources used to spread messages on a larger scale. This fact has allowed the presence of various Korean cultural products, derived from Hallyu, in different parts of the world, as would be the case in some Latin American countries, and especially in Mexico. The ideas presented here are the result of an extensive bibliographic review and are part of a postgraduate research project whose main objective is focused on analyzing consumer practices by Mexican people who consider themselves fans of this industry. As will be shown throughout this proposal, the organized fans have played an extremely important role in the expansion and consumption of the different cultural manifestations of Hallyu. Thus, a large part of the information that makes up this text derives from the state of the art examined for the construction of the aforementioned project. It is also extracted from a series of empirical examples that have taken place, above all, in the Mexican context, which allow observing the close interactions between Korean celebrities and their fans, thanks to the usage and meaning that has been attributed to socio-digital networks today.

\section{Keywords}

Korean Wave; Cultural Industry; Creative Industry; Fangagement; Sociodigital Networks; K-Pop; K-Drama.

\section{La Ola Coreana. Algunos datos generales}

El Hallyu -en coreano 한류 u Ola Coreana en español- es el término que se le ha asignado a la industria cultural proveniente de Corea del Sur, compuesta por distintas manifestaciones entre las que destacan, por su relevancia e impacto, la música (denominada como K-pop), las telenovelas (K-dramas), la moda, el idioma, el cine, los artículos de belleza y cuidado personal (K-beauty) y la gastronomía. Estas manifestaciones han alcanzado dimensiones globales debido a la difusión que se ha hecho de ellas gracias al uso y la incorporación de las nuevas tecnologías de la información, tanto para su producción, como para su difusión masiva, trascendiendo las fronteras de Corea del Sur y del mismo continente asiático (Molnar, 2014; Bok-Rae Kim, 2015, 2018).

El uso del término Hallyu (que de acuerdo con Constanza Jorquera [2016] está compuesto por dos caracteres chinos: Han [韓]- Corea y Lyu [流]- río) se le atribuye a la prensa china, que a mediados de los años noventa empezó a utilizarlo para "describir el impacto que estaba causando la industria coreana del entretenimiento en China" (Jorquera, 2016, p. 4).

Si bien no es la intención de este texto hacer un recorrido histórico del Hallyu, es importante recordar que fue la cultura japonesa, acorde a los estu- 
dios realizados por Bok-Rae (2018), la que sentó las bases para la creación y el desarrollo de la denominada cultura popular coreana. Durante el periodo colonial japonés -que comenzó en 1920 y encontró su final en el año 1945-, los medios masivos de comunicación fueron introducidos en Corea, principalmente los periódicos y la radio, dispositivo que a la larga impulsaría a la industria discográfica y que empezaría a perfilar lo que años más tarde sería identificado mundialmente como Ola Coreana. Es conveniente apuntar desde ahora que la música -K-pop- y sus múltiples representantes -artistas en solitario y una gran variedad de boys o girl bands- constituyen los pilares fundacionales que sostienen y proyectan esta gran industria cultural.

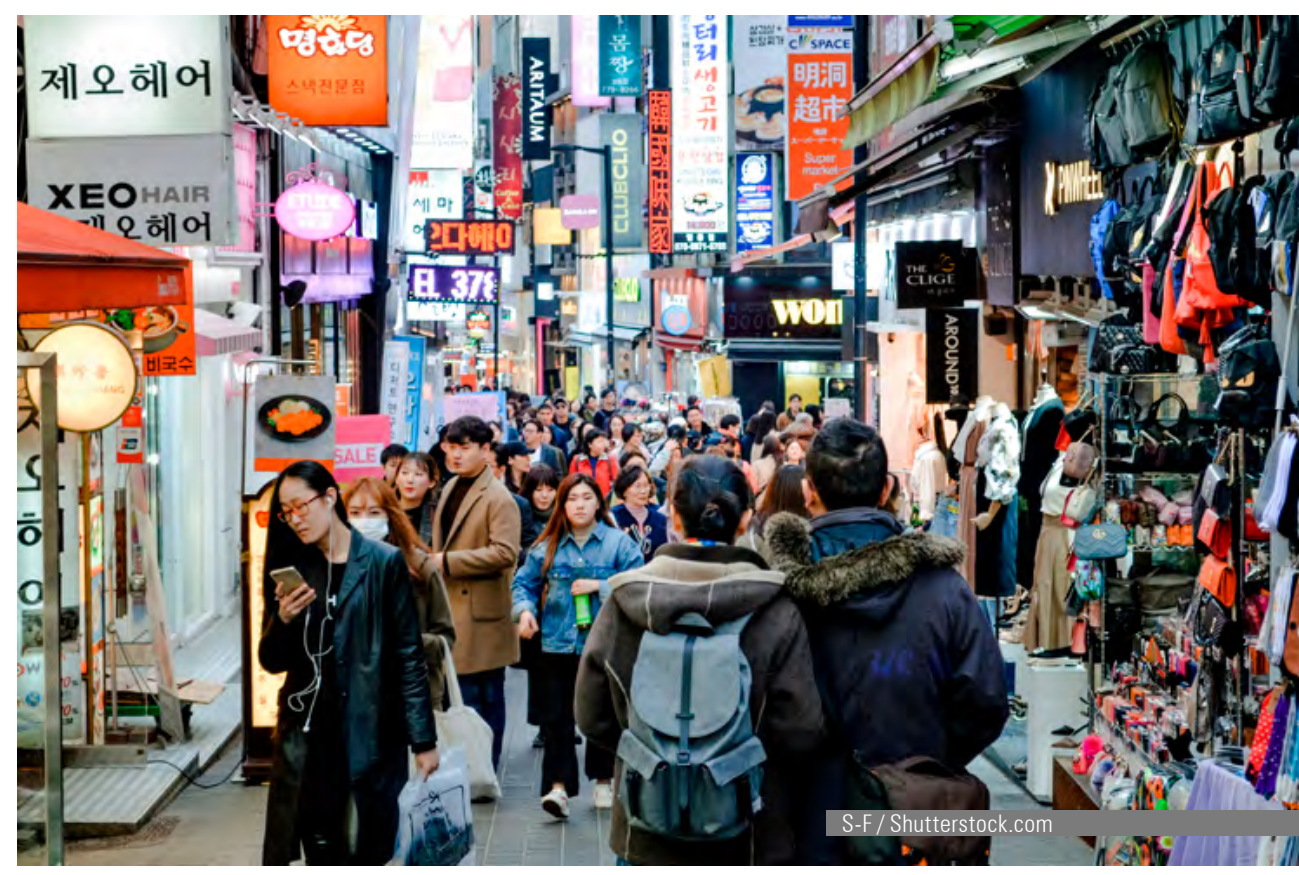

A partir de 1945 y hasta el día de hoy, la influencia estadounidense en la cultura popular coreana es palpable. En sus esfuerzos por crear una industria cultural propia y poderosa, los coreanos emularon y, de algún modo, se apropiaron "del sistema de medios estadounidense bajo el mantra 'aprender de Hollywood', argumentando que Corea debería promover grandes empresas, así como un mercado de medios que fuera mucho más comercial" (Shim, 2006, p. 32). Mediante este proceso de influencia y aprendizaje -que autores como Doobo Shim (2006) califican como de hibridación cultural-, los coreanos han aportado y adecuado sus propios elementos culturales a los distintos estilos procedentes del extranjero, al mezclar e incorporar características provenientes de sus tradiciones ancestrales a formas un tanto más innovadoras y actuales. Basta con echar un vistazo a la transformación que ha experimentado la música 'pop' coreana -sobre todo a partir de la década de los años 90- gracias a la interesante combinación de las tendencias globales occidentales y de las bases tradicionales de la música coreana. Así pues, un punto clave del éxito de los procesos de industrialización y masificación que detonarían la conformación, popularidad y consolidación de la Ola Coreana, fue la instauración de una sociedad capitalista de consumo en Corea del Sur durante las décadas de 1960 y 1970, época en la que los jóvenes y los adolescentes fueron considerados como los consumidores en potencia para las distintas industrias emergentes (Gutiérrez, 2006; Shim, 2006; Bok-Rae Kim, 2015, 2018). 


\section{Fases del Hallyu}

Es relevante anotar que la Ola Coreana ha transitado por distintas fases para lograr afianzarse dentro del gusto del público coreano y no coreano, en el caso particular de este texto, del latinoamericano. De acuerdo con Mauro Neves (2018) la primera de estas fases -que surgió sin planearse- comprende desde los Juegos Olímpicos de Seúl en 1988 hasta finales de los años noventa. Esta fue la primera vez que Corea del Sur mostraría al exterior parte de su cultura local aprovechando la exposición internacional que el ser organizador de un evento deportivo de tal magnitud traía consigo, lo cual le serviría más adelante para convertirse en lo que se conoce como Marca País, término que ha cobrado trascendencia en los análisis que se han elaborado a partir del caso de Corea del Sur, y que se refiere "al valor intangible de la reputación e imagen de un país a través de múltiples aspectos, que determinan los valores que se le asocian" (CEUPE, s.f.).

Entre los factores que constituyen una Marca País -algunos de los cuales se posicionan como componentes de la Ola Coreana-, se destacan la cultura, la música, el folclore, las tradiciones, la gastronomía típica, los deportes y la oferta turística, entre otros (Juárez Postigo, L.; Blasco López Mª F. \& Blázquez Jiménez J. A., 2015).

Siguiendo con las etapas de la Ola, en el año 2002 la Copa Mundial de Fútbol de la FIFA fue organizada por Corea del Sur y Japón en conjunto. En este periodo se gestó y tuvo lugar la segunda fase del Hallyu -según registra Neves (2018)-, cuyo suceso más exitoso correspondió al K-drama Winter Sonata o Sonata de Invierno -título con el cual se dio a conocer esta serie televisiva en español-, compuesto por veinte capítulos y transmitido en 2002 por la cadena de televisión coreana KBS 2TV. Actualmente se considera que la difusión de este drama fue el acontecimiento más representativo de la segunda etapa de la Ola Coreana y marcó el inicio de la salida de las manifestaciones culturales coreanas hacia otros lugares del mundo, pues su recibimiento en Japón -por citar un ejemplo- fue tan bueno que logró desplazar a la industria del entretenimiento japonesa', sin dejar de mencionar su emisión en veinte países distintos, entre los que destacan Malasia, Estados Unidos, Colombia, Perú, Venezuela y México.

\section{Grupos públicos de interés en la Ola Coreana}

Luego de la instauración de la segunda etapa en el año 2002, conviene traer a colación la categoría "grupos públicos de interés" propuesta por Trevor Pinch y Wiebe E. Bijker (1984), la cual resulta de especial utilidad para complementar la descripción de las siguientes fases del Hallyu, en las que la tecnología y los medios de comunicación desempeñan un papel fundamental. Los sociólogos antes referidos plantean que "los grupos públicos de interés se encuentran integrados por instituciones, organizaciones, así como por individuos organizados o desorganizados donde el requisito clave de todos los miembros es sostener el mismo conjunto de significados para un mismo artefacto" (Pinch y Bijker 1984 en Santos, 1994, p. 400). Si bien es cierto que los autores que propusieron tal categoría la emplearon para referirse al desarrollo de la bicicleta como un artefacto tecnológico en un contexto determinado, la categoría es favorable para trasladarla al caso de la Ola Coreana, que se ha valido de los recursos y herramientas tecnológicas para producir y difundir con mayor alcance e inmediatez determinadas manifestaciones culturales a

\footnotetext{
1 Se estima que el impacto del K-drama representó ingresos al país por 27 mil millones de dólares, 840 billones de wons en turismo y 30 billones de wons en ventas de mercadotecnia, esto según una nota del 14 de abril de 2015 en The Korea Observer [http://www.koreaobserver.com/bae-yong-joon-to-makewinter-sonata-sequel-later-this-year-28003/].
} 
fin de ser consumidas por distintas audiencias, tal como veremos enseguida. Los medios de comunicación masiva y las nuevas tecnologías de la información son producidos y controlados, en su mayoría, por la iniciativa privada, mientras que buena parte de los gobiernos continúan implementando programas o proyectos enfocados en conservar y reforzar el patrimonio tradicional de sus naciones, y en desarrollar y promover actividades artísticas y folclóricas cuya baja rentabilidad en el mercado suele complicar su subsistencia (García Canclini, 1987). No obstante, para el caso particular de la Ola Coreana, está claro que existe un común acuerdo o un mismo significado que es compartido por distintos grupos y que está puesto en un solo objetivo: Impulsar a la cultura-coreana- por medio de sus diversas manifestaciones como un recurso que es rentable y redituable, pues tal como lo señala Urteaga (2012):

la digitalización influye en la creación, producción, consumo y distribución de una variedad de servicios, objetos y productos culturales, impulsando la conversión de la cultura en un negocio. A su vez, los nuevos servicios culturales demandan la reconversión digital de las empresas y de los agentes involucrados en la producción cultural (p. 38).

Para ilustrar, a raíz del éxito del K-drama Winter Sonata y en adelante, ciertas agencias del gobierno coreano comenzarían a trabajar de la mano con empresas privadas de entretenimiento con la intención de impulsar la popularidad del Hallyu, tomando como punto de partida los países ubicados en el Este asiático. Inicialmente se incentivaría la Ley de Promoción de la Industria Cultural Básica y la creación de la Agencia Coreana de Cultura y Contenidos (Arrioja \& Réquiz, 2018). Más adelante se formalizaría al Hallyu como una estrategia de soft power (Jorquera, 2016) o poder blando, ${ }^{2}$ lo que desembocaría en la participación formal e institucional del Ministerio de Cultura, Deportes y Turismo por medio de la KOCCA (Korean Creative Content Agency) y la KOFIC (Korean Film Council) (Jorquera, 2016; Arrioja \& Réquiz, 2018). Una de las primeras acciones que este equipo llevó a cabo, y que resultó sumamente eficaz, fue la de etiquetar todas las exportaciones de entretenimiento coreano bajo el título ' $K$ ', por ejemplo: $K$-drama, K-pop y K-fashion o K-beauty. Esta estrategia permitió a los consumidores -provenientes de distintos países del mundo- identificar fácilmente el lugar de origen de sus productos (Lee, 2019; Cremayer, 2020).

Dentro de esta compleja red de grupos interesados en la rentabilidad generada por la cultura coreana, también se consideraría relevante la participación del Consejo Nacional de Marcas, y para el año 2009 se crearía la Comisión Presidencial de la Marca País en Corea (Arrioja \& Réquiz, 2018; Neves, 2018). Sin embargo, estudios realizados por Sue-Jin (2011), Bok-Rae $(2015,2018)$ o Lee (2019) plantean que la Ola Coreana no siempre ha sido bien recibida en otros países, surgiendo movimientos que los autores antes señalados catalogan como antihallyu y que han cobrado fuerza en distintos lugares, por lo que la recepción de esta industria cultural no siempre se ha dado con las puertas abiertas plenamente.

Habiendo dejado claro lo anterior, la tercera etapa del Hallyu -ya con una formal intervención gubernamental- empezaría por reforzar las estrategias de poder blando aplicadas en los países del Este asiático a través de la implementación de las tecnologías de la información y la comunicación (TIC). Un ejemplo de suma relevancia que demostró la eficacia de las estrategias empleadas por los grupos de interés detrás de la Ola Coreana, fue la difusión

2 Para Joseph Nye (1991) el término se refiere a la habilidad para convencer a otros de hacer lo que uno quiere por medio de la atracción, y no por la coerción o por pagos. "Este poder se enmarca en tres tipos de recursos: su cultura, haciéndola atractiva para otros; sus valores o ideales políticos, internos y en el exterior; y su política exterior, especialmente para ganar legitimidad y autoridad moral" (Mejía, 2015, p. 12). 
masiva -vinculada estrechamente con el uso de las redes sociodigitales- del videoclip de la canción Gangnam Style, del artista surcoreano PSY. El video cuenta con más de cuatro billones de visualizaciones en la plataforma YouTube desde su publicación, el 15 de julio del año 2012. Este hecho resulta significativo para el tema que aquí se está abordando, puesto que en aquellos años era relativamente desconocido el impacto que tenía el Hallyu en Latinoamérica. Sin embargo, para el año 2014, un estudio realizado por Korea Foundation -organización que también se encarga de promover aspectos culturales de Corea en diferentes países a través de programas académicos o "de patrocinios para exportar numerosos dramas o telenovelas al exterior como otro canal de conocimiento de Corea del Sur" (Uscanga, 2014, p. 159)daría a conocer que "América contaba con el mayor aumento de número de fandoms ${ }^{3}$ o grupos de fanáticos de Hallyu a nivel global, alcanzando ya las 715 organizaciones [para ese entonces]. Los países con mayor número de fandoms son Perú, Chile y México" (Jorquera, 2016, p. 4).

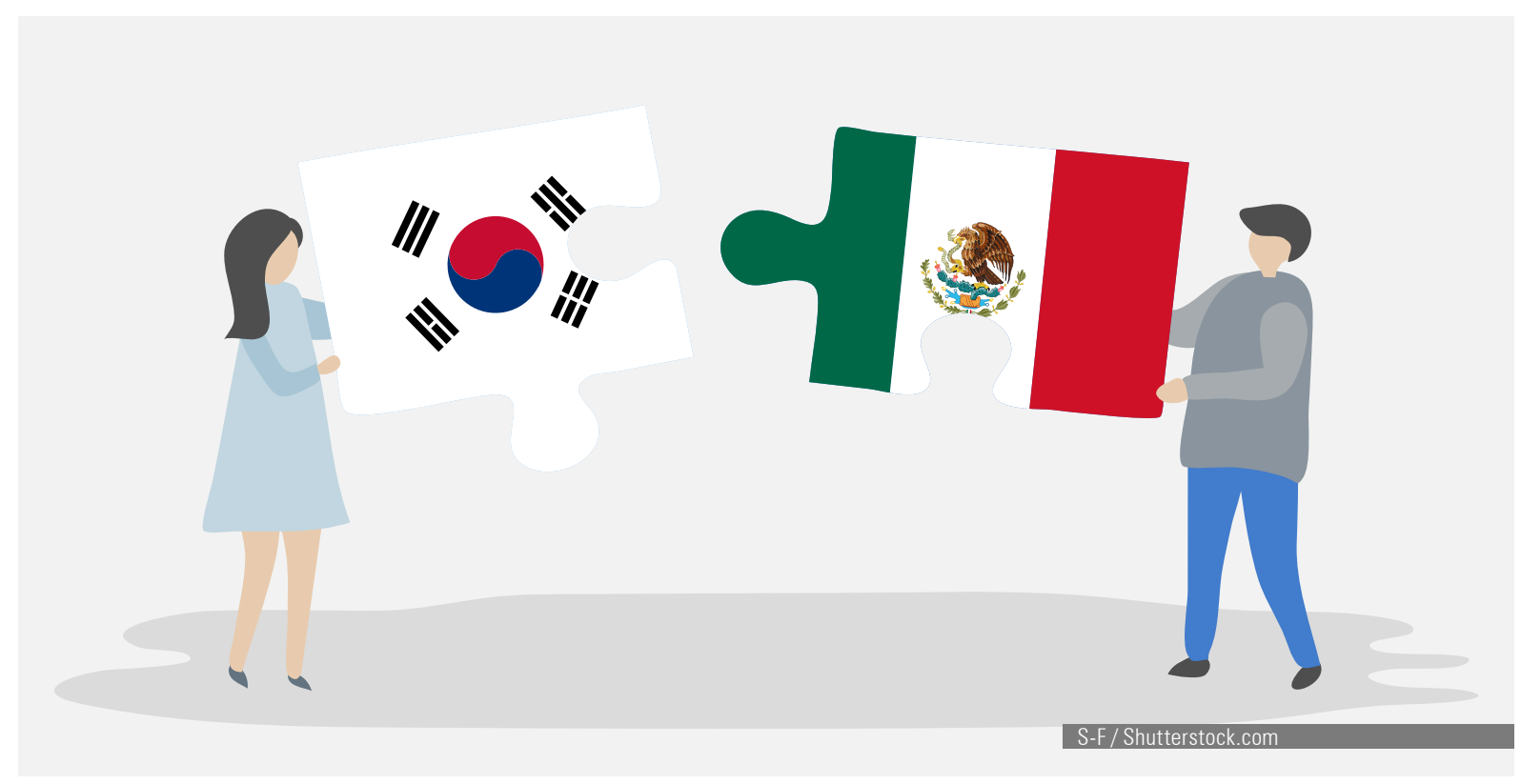

Adicionalmente, fue en este tercer periodo cuando se incluyó en los planes estratégicos del soft power al continente americano y se crearon diferentes Centros Culturales Coreanos (CCC) situados en varios países de América Latina, entre los cuales se incluyó a México. Estos Centros Culturales son los encargados de realizar y promover distintos eventos relacionados no solo con el Hallyu, sino con la cultura coreana en sus aspectos más tradicionales. También imparten diferentes talleres para incentivar el aprendizaje del idioma coreano o de su gastronomía típica, organizan conferencias especializadas en temas de interés general sobre Corea y ofrecen pláticas de orientación académica en sus instalaciones acerca de los procesos de admisión para que aquellos estudiantes que deseen postularse para obtener una beca dentro de uno de los programas de licenciatura o posgrado en alguna institución de Corea del Sur, sepan cómo hacerlo. Es preciso añadir que la difusión y la promoción que se hace de los eventos antes mencionados y otros tantos

3 El fandom comprende la comunidad global conformada por fans que comparten el gusto, admiración 0 afición por algo 0 alguien en particular. El fandom promueve y provee sentimientos de identidad y colectividad entre sus miembros, quienes suelen estar orientados a la realización de ciertas actividades relacionadas con el interés que los mantiene unidos (Thompson, 1998; Turriza, 2019). 
más, se vale del uso de las redes sociodigitales y de páginas oficiales, ya sea de los propios Centros Culturales Coreanos, de las embajadas y de algunos otros medios -como revistas, blogs y canales de YouTube- a fin de lograr un mayor alcance y resonancia de los mensajes que desean transmitir a los miembros de su audiencia. Hay que destacar que, en ocasiones, algunas de las actividades culturales desarrolladas bajo la organización del Centro Cultural Coreano en México han sido tan populares entre el público que la misma televisión abierta -percibida al día de hoy como un medio de comunicación masivo tradicional-, se ha encargado de brindarles espacios de difusión dentro de su propia programación. Algunos casos son el Canal 22 y Proyecto 40, registros audiovisuales que pueden encontrarse todavía en el canal oficial de YouTube del CCC México.

Es posible apreciar con nitidez, a partir de este punto, el gran empuje que se le estaba otorgando al rol casi protagónico que desempeñarían en adelante las tecnologías de la información y la comunicación, y el uso de las redes sociodigitales, en dirección hacia el éxito transnacional del Hallyu. Incluso Vidal (2014) propone que con la masificación -más no democratización- de internet en los últimos años y la aparición de la plataforma de videos YouTube, "el K-pop (pieza clave del Hallyu como se señaló anteriormente) se hizo mucho más accesible y 'viralizable' para las personas (que empezaban a estar más) interesadas en la cultura coreana" (p. 15).

Probablemente fue en este instante registrado por Vidal (2014) cuando el Hallyu pasó de ser una industria cultural a una industria creativa digital, que refleja "la influencia de las tecnologías digitales en la creación y el desarrollo de nuevas expresiones culturales" (Secretaría de Cultura, 2018, p. 8). Para respaldar esta afirmación, es imprescindible recurrir a la definición amplia de las industrias culturales y las industrias creativas que, de acuerdo con la UNESCO (2009), encuentran elementos coincidentes, y que son entendidas como "aquellos sectores de actividad organizada que tienen como objeto principal la producción o la reproducción, promoción, difusión y/o la comercialización de bienes, servicios y actividades de contenido cultural, artístico o patrimonial" (p. 1). La dimensión en común que compartirían estas industrias culturales y creativas -la salida al mercado, la promoción y la difusión- es la que le otorga la facultad a esta definición de utilizar sus concepciones y poder aplicarlas al caso de la Ola Coreana. Asimismo, el que sus manifestaciones culturales -como los K-dramas, el K-pop e incluso la gastronomía y el K-beauty- tuvieran la capacidad de entrar en una "dinámica de digitalización" (UNESCO en Secretaría de Cultura, 2018, pp. 52-53) no hizo más que expandir esta industria alcanzando públicos más amplios, pues el propósito ahora, con la incorporación y el uso cotidiano de las tecnologías, está enfocado en que las personas interesadas en este tipo de bienes puedan consumirlos rápidamente a través de distintos dispositivos digitales y desde distintos lugares del mundo gracias al acceso que se tiene a internet. Está claro que ni la gastronomía ni el llamado K-beauty cuentan -todavía- con los recursos tecnológicos suficientes para digitalizarse, pero la promoción que se ha hecho de estas manifestaciones culturales a través de las redes sociodigitales -especialmente en plataformas como YouTube- ha sido indispensable para despertar el interés en conocerlos y más tarde en consumirlos, o al menos en imitarlos en países con tradiciones culinarias muy diferentes a las coreanas, para el caso de la gastronomía. Respecto a los cosméticos, los productos de belleza y de cuidado personal, también existe una gran difusión por parte de los llamados 'creadores de contenido', que no hacen más que alentar a los consumidores, quienes se dan a la tarea de conseguir -en tiendas físicas establecidas en sus países o mediante compras en sitios de internet especializados- mascarillas, cremas y otros artículos para el cuidado y el aclarado de la piel, principalmente del rostro, algo que al parecer es muy importante y 
apreciado dentro de los estándares de belleza coreanos, tal como se observa en los dramas y en el aspecto de la mayoría de los idols y las celebridades surcoreanas. En México, particularmente, es posible encontrar estos artículos catalogados como de K-beauty en establecimientos especializados, algunos de ellos ubicados estratégicamente en el área que se ha constituido como el 'barrio coreano', que comprende las calles de la llamada Zona Rosa en la Ciudad de México. El surgimiento en años recientes de este 'barrio coreano' en uno de los lugares más populares, céntricos y concurridos de la capital mexicana, se debe a la fuerte presencia de comercios como restaurantes, cafeterías, karaokes, pequeños supermercados y tiendas dedicadas a la venta de productos de moda y belleza coreanos. Aunado a esto, es notable el aumento de academias o clases impartidas por profesores nativos que tienen como objetivo la enseñanza del idioma coreano, y que suelen promocionarse a través de carteles o anuncios exhibidos en los comercios antes descritos.

El conjunto de estas manifestaciones culturales contenidas en el Hallyu, y que son transportadas masivamente a través de los distintos medios tecnológicos de los que se dispone hoy en día, sin lugar a dudas ha sido una acción acertada para que los grupos públicos de interés (Pinch y Bijker, 1984), integrados por la iniciativa privada y algunas dependencias del gobierno coreano, encuentren audiencias más amplias deseosas de consumir aspectos particulares de la cultura coreana, todos ellos etiquetados bajo la rúbrica ' $K$ '. Por lo tanto, en este contexto social marcado por un intenso consumismo que dibuja y define el entorno "el mercado responde a las expresiones de gusto y del deseo popular y a las identidades que la gente prefiere, intentando producir más de eso mismo" (Winner, 2004, p. 60). Quizá esta idea de Langdon Winner encuentre sintonía en propuestas tan clásicas, pero no por ello menos vigentes, como las plasmadas hace algunas décadas en la tesis de Walter Benjamin (1953), en la que se retoman los postulados de Adorno y Horkheimer, particularmente aquel que invita a no perder de vista la existencia de una masa que es "manipulada al antojo de los managers de un monstruoso sistema generador de gustos y opiniones cuya meta obsesiva es la reproducción, en infinidad de versiones de todo tipo, de un solo mensaje que canta la omnipotencia del capital" (Benjamin, 2003, p. 25 originalmente publicado en 1935). De este modo, el aprovechamiento de este contexto actual caracterizado por la proliferación de una gran cantidad de ecosistemas tecnológicos (Morley, 2008; Díaz y Roque, 2014) y digitales (Katz, 2015) en el que se sobrevalora el consumo, no ha hecho más que favorecer y confirmar el fortalecimiento y la presencia del Hallyu dentro y fuera del territorio surcoreano, pues una gran parte de lo que hoy en día se podría concebir como cultura de masas se gesta en el ciberespacio, al cual acceden los usuarios mediante distintos tipos de dispositivos que son cada vez más sofisticados, y que permiten mayores grados de interacción y colaboración entre creadores y consumidores.

\section{Fangagement. Interacción y compromiso entre las celebridades coreanas y sus fans}

Para retomar las etapas del Hallyu, Mauro Neves (2018) propone que la cuarta fase bien puede ser denominada como el Hallyu 2.0, la cual implicaría la participación en la Ola Coreana de personas de todo el mundo gracias al uso cotidiano de las redes sociodigitales. Otra de las características que este autor considera importante dentro de lo que es el Hallyu 2.0, es la producción de contenido coreano con características de esta cultura, pero realizado fuera del territorio de Corea del Sur. Esto como resultado -nuevamente- del uso de las redes sociodigitales en favor de la difusión de la Ola Coreana por 
parte de los fans de esta industria creativa digital. ${ }^{4}$ Para ahondar un poco más en esta cuestión, es oportuno traer a la mesa de la discusión una categoría elaborada y propuesta por Brandon Lee Houlsby (2019), la cual no ha sido desarrollada del todo pero que, con algunas aportaciones que complementan su definición inicial, se percibe como elemental para conseguir un mejor entendimiento del fenómeno social fan derivado de la masificación de la Ola Coreana: el fangagement.

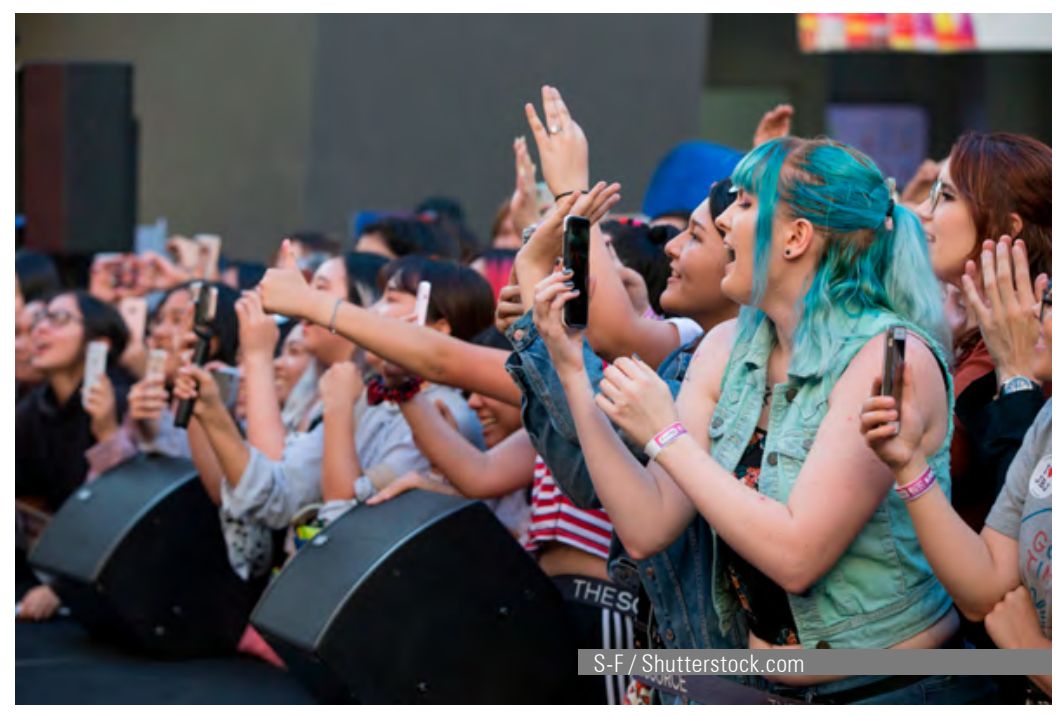

De acuerdo con los primeros esbozos que ofrece Lee (2019), el fangagement es útil para expresar el alto grado de interacción que existe hoy en día entre las celebridades coreanas y los miembros de sus audiencias, producto del uso cotidiano de las diferentes redes sociales digitales disponibles. ${ }^{5}$ Este ejercicio se manifiesta de mejor forma cuando los grupos de fans o fandoms adquieren el compromiso de centrar buena parte de su tiempo en promocionar a sus artistas coreanos favoritos mediante la implementación de distintas estrategias creativas y colaborativas que suelen echar mano, principalmente, de las redes sociodigitales como herramienta de comunicación e integración, pero también como escenario en el que muestran y despliegan el compromiso adquirido. Para echar a andar este ejercicio adecuadamente, es indispensable que los fans -pertenecientes a los distintos fandoms que existen- comprometidos con la consecución de una meta en común, destinen cierta cantidad de recursos, que van desde lo económico hasta la inversión de su tiempo, a la realización de una serie de tareas que se proponen concretar en conjunto, como a menudo se puede observar en las redes sociales, cuando, por ejemplo, se lleva a cabo un trabajo colectivo -en ocasiones incluso con la participación y el involucramiento de los mismos ido/s- para tratar de que el nombre de su artista favorito se convierta en una tendencia mundial, aunque el fangagement no se limita solo a posicionar a las celebridades surcoreanas en el ciberespacio, tal como se expondrá a continuación.

4 Para el quinto periodo, "el gobierno coreano ha puesto en marcha el K-culture Promotion Task Force, que tiene como finalidad ayudar a iniciar la era del 'Hallyu 3.0', fijando su objetivo inicial en el 'desarrollo creativo de la cultura tradicional' (Ryzhkov, 2014 en Arriojas \& Réquiz, 2019, p. 47). Esta fase integra ya, de manera formal, a la industria de belleza y el sector turismo; también da pie al Han Style, que tiene como propósito dar a conocer aspectos más tradicionales sobre la cultura coreana.

5 Es pertinente acotar que en su texto All eyes on Seoul: A study of the Korean Wave del 2019, Lee Houlsby analiza el fangagement desde el rol que desempeñan las celebridades coreanas, sin profundizar demasiado en el papel que llevan a cabo los fans, el cual, de acuerdo con nuestra observación y recopilación testimonial, es clave para que este ejercicio siga funcionando. 
Los mismos miembros que configuran y dan sentido a estos fandoms o grupos de fans, son quienes frecuentemente se encargan de traducir y/o subtitular del idioma original coreano al idioma en el que estas comunidades consumen los materiales audiovisuales, algunos videoclips de canciones, entrevistas de artistas coreanos y en otros casos aún más representativos series completas de televisión -K-dramas-, como se refleja en la circunstancia particular del servicio de streaming llamado Viki, en donde es posible dar cuenta del trabajo colaborativo emprendido por distintos "equipos" de fans que contribuyen en la traducción y el subtitulado del contenido que en dicha plataforma está disponible.

Asimismo, existe un sitio de internet llamado Soompi, el cual está enfocado básicamente en presentar las noticias más recientes y relevantes sobre la cultura pop de Corea del Sur. Este ejemplo resulta sumamente ilustrativo para lo que aquí se está argumentando, debido a que Soompi se sostiene y se enriquece gracias a las constantes aportaciones de diferentes fans alrededor del mundo que trabajan continua y comprometidamente para mantener un adecuado funcionamiento dentro del sitio. Este esfuerzo implica a todas luces que, muy probablemente motivados por algunas de las distintas manifestaciones culturales constitutivas de la Ola Coreana, ciertas personas busquen los medios necesarios para aprender el idioma coreano, ya sea inscribiéndose a un curso presencial -algo que se puede hacer en lugares como los Centros Culturales Coreanos, de forma gratuita para el caso particular de México-, descargando aplicaciones de idiomas ${ }^{6}$ o viendo tutoriales que están disponibles en internet, al tiempo que desarrollan o mejoran sus habilidades tecnológicas o simplemente dinamizan sus cualidades, todo con el propósito de aportar a la difusión y al acceso de estos contenidos derivados de la Ola Coreana.

Es importante señalar dos cuestiones antes de seguir analizando al fangagement. La primera de ellas es la trascendencia que han tenido los K-dramas para la difusión y por ende el consumo de otras manifestaciones culturales del Hallyu. El Centro Cultural Coreano en México ha informado que, desde al año 2002, se han transmitido en este país nueve K-dramas gracias al vínculo y a las negociaciones que se han establecido con cadenas estatales de televisión abierta, como el Canal 34 de Tv Mexiquense, o canales locales de los estados de Michoacán, Puebla, Nuevo León, Campeche y Jalisco (Mérida, 2015). En este sentido, gracias al desarrollo tecnológico que ha acompañado al Hallyu desde su creación y durante sus distintas etapas de expansión, Lee (2019) propone que en años recientes algunas compañías coreanas de creación y publicación de contenidos digitales se han asociado exitosamente con las plataformas occidentales de servicios de transmisión, como Netflix o AmazonPrimeTV, con el propósito de producir, distribuir y promocionar sus programas y películas coreanas a través de dichos servicios. Esto sin dejar de lado la existencia de aplicaciones creadas exclusivamente para alojar y exhibir los contenidos antes referidos, como ese enorme acervo digital de series coreanas que albergaba Viki, y la extinta plataforma DramaFever.

En consecuencia, los K-dramas han jugado un papel muy importante en la diseminación del Hallyu, pues fueron las mismas telenovelas coreanas "las que en un principio fungieron como una especie de vehículo de la música pop coreana, ya que esta formaba parte de los melodramas al ser incluida como banda sonora de estas producciones" (Vidal, 2014, p. 11). Es así que se retomarán algunos ejemplos concretos relacionados con el K-pop a fin de seguir exponiendo el compromiso de los fans -al cual se ha acordado

6 Es interesante subrayar el caso de MEEFF, una aplicación para conocer amigos coreanos y practicar el idioma coreano que ha suscitado algunas controversias a su alrededor, pues existen comentarios en las redes sociodigitales de usuarios que aseguran ha pasado a ser un entorno que al parecer favorece el intercambio de materiales audiovisuales de contenido sexual. 
nombrar en este texto como fangagement- en la promoción de este elemento primordial para la Ola Coreana: la música pop.

Brandon Lee Houlsby (2019) enfatiza que las empresas coreanas son conscientes de la forma en la que manejan a sus artistas, además de la cercana y estrecha relación que dichas celebridades mantienen con sus fans. Esta situación es terreno fértil para que se fomente y se sostenga una continua creación de contenidos o productos dirigidos estratégicamente para que el fandom en cuestión siga interesado e involucrado con el artista que admira, observando, además, que su trabajo como fan comprometido con la causa común será recompensado de alguna u otra manera en determinado momento.

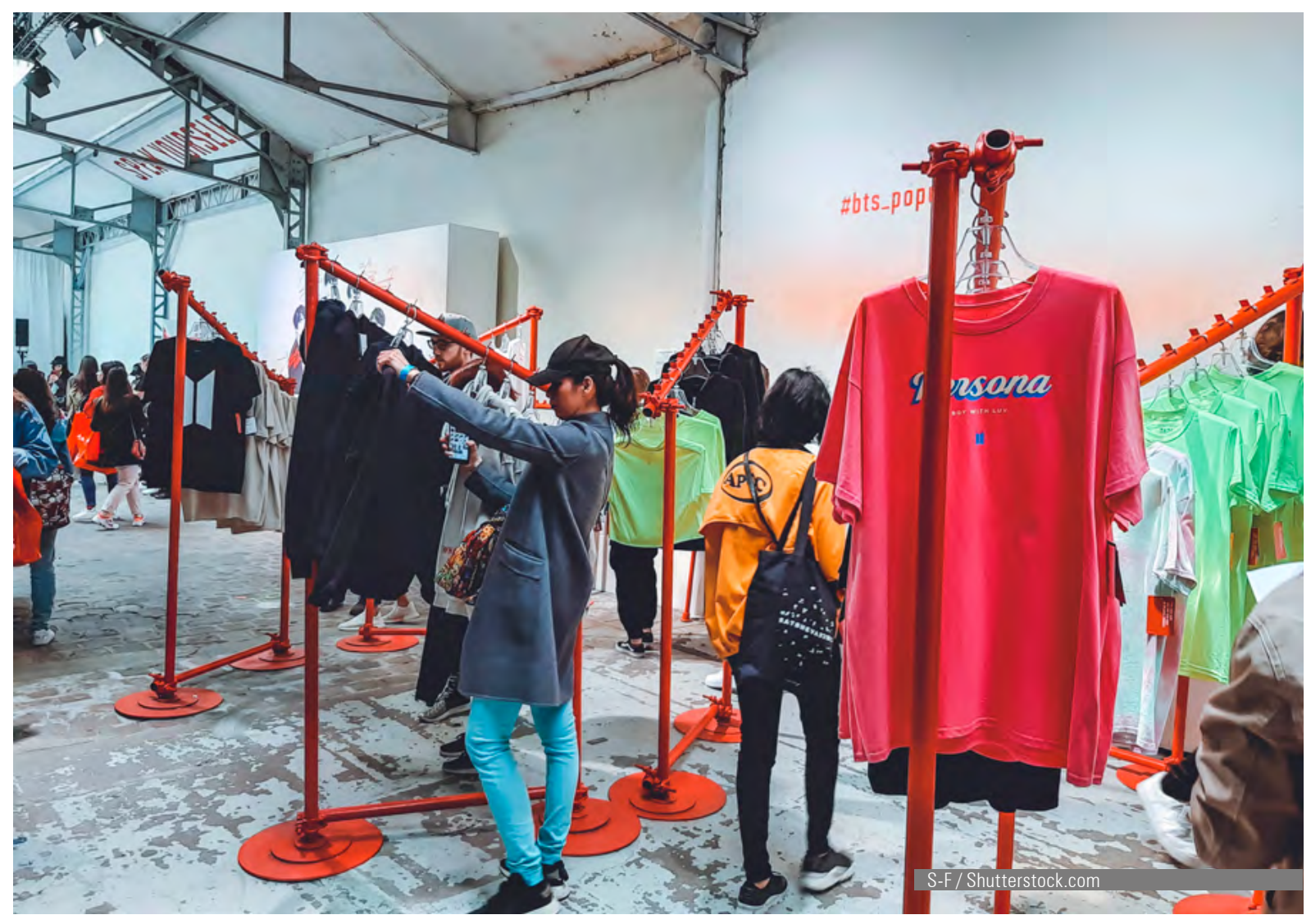

Tal es el caso de la tienda BTS POP-UP: House of BTS de la banda de K-pop BTS. Dicho establecimiento abrió sus puertas del 13 de diciembre de 2019 al 26 de enero de 2020, y estuvo ubicado en una de las zonas más exclusivas de la Ciudad de México. Cabe resaltar que esta boutique fue la primera tienda oficial de la agrupación que se inauguró fuera del continente asiático, y como lo publicó en una nota el periódico La Verdad (2019):

el ARMY -fandom- mexicano se ha caracterizado por ser uno de los más fuertes de toda Latinoamérica y por esa razón han sido recompensadas (regularmente los grupos de fans de las bandas de K-pop están conformados en su mayoría por mujeres, aunque curiosamente esta nota asume o da por sentado que el ARMY mexicano está integrado únicamente por mujeres al hacer alusión a que son ellas las que han sido recompensadas) con la llegada de la tienda oficial de la agrupación en donde podrán adquirir todos los productos que BTS ha lanzado al mercado mundial (párr.2). 
Aunque la nota no lo menciona textualmente, se intuye que las redes sociodigitales jugaron un papel fundamental al momento de tomar la decisión de abrir la tienda en México y no en otro de los países que habían sido contemplados en América Latina, como lo fue el caso de Brasil. Al parecer el fandom mexicano ejerció una fuerte presencia en las redes logrando que el establecimiento se trasladara directamente a la capital mexicana y así, los fans -mexicanos y extranjeros que se desplazaron hasta México solo para poder ser parte de esta experiencia- tuvieran la oportunidad de asistir al evento de apertura, adquirir productos oficiales que inclusive habían sido diseñados con motivos mexicanos, y registrar su experiencia en las distintas redes publicando fotografías y videos -que compartían con fandoms de otros países del mundo- en los que mostraban sus adquisiciones y el agradecimiento a la banda por haber tomado en cuenta a su país.

Otros sucesos interesantes que reflejan el compromiso de los fandoms y el alcance internacional que ha logrado la Ola Coreana tuvieron lugar durante la pandemia de covid-19, la cual ha transformado radicalmente las prácticas sociales y culturales desde su aparición global a partir del año 2020, algo que no ha resultado un impedimento para que el Hallyu siga exportando sus manifestaciones por medio del uso de las tecnologías.

El 31 de mayo del 2020 la agrupación de K-pop Super Junior ofreció un concierto online a través de la plataforma $V$-live. El espectáculo resultó ser todo un éxito gracias a la respuesta del público, pues un aproximado de 120.000 personas localizadas en distintas partes del mundo tuvieron la oportunidad de presenciar el show en vivo - viendo al mismo tiempo la transmisión desde sus países de residencia- previo un pago de por medio (alrededor de $\$ 30$ USD, aproximadamente $\$ 570$ MXN). Además, cabe recalcar que el fandom 'E.L.F' -Ever Lasting Friends, nombre oficial con el que se identifica mundialmente al club de fans de Super Junior- logró romper el récord de la mayor cantidad de corazones ${ }^{7}$ enviados en la plataforma hasta ese día, ya que según la agencia de noticias Yonhap (2020) se recibieron alrededor de 2.850 millones de corazones durante la transmisión. Hay que retomar aquí el planteamiento de esas relaciones estrechas que se dan entre fans y artistas observadas por Lee Houlsby (2019), puesto que algunos fans de Super Junior tuvieron la oportunidad de interactuar directamente con los ido/s por medio de video llamadas, mientras que otros tantos aparecieron en las pantallas del escenario, todo esto durante el concierto que se llevó a cabo en la fecha antes citada.

Por su parte, el 14 de junio del 2020 la banda BTS realizó un concierto que reunió a más de 750 mil espectadores en línea provenientes de más de 107 países del mundo, destacando la presencia de fans del continente americano, quienes sumaron la nada despreciable cantidad de más de 90 mil personas conectadas para disfrutar el evento, superando incluso a la audiencia en conjunto de Corea del Sur y Japón, según se puede apreciar en un mapa interactivo que, a través del encendido del lighstick oficial del grupo -artefacto luminoso que se ha convertido en un elemento casi de identidad ${ }^{8}$ dentro de algunos fandoms dependiendo de su forma y color-, marcaba la ubicación en tiempo real de los fans que presenciaban el concierto, todo esto de acuerdo a un reporte realizado por el blog thehallofstars.com (2020). No es un dato menor hacer una pequeña descripción del papel fundamental que jugó la tecnología para hacer este evento posible, pues gracias al desarrollo de un sofisticado programa, los fans de BTS que contaran con un lighstick oficial -y con el boleto que les daría el acceso a la transmisión del concierto

7 Botones sociales que indican, en este caso, que el contenido está siendo del agrado del espectador.

8 Para Langdon Winner (2004) "Los bienes de consumo se han convertido en medios a través de los cuales las personas se expresan a sí mismas: lo que compran, lo que visten, lo que poseen y lo que usan es un símbolo de sus vidas" (p. 60). 
cuyo costo para el público general fue de \$35 USD y para los miembros del fandom oficial de la banda de \$26 USD aproximadamente, según se observa en la nota elaborada por thehallofstars- tenían la oportunidad de sincronizarlo de forma tal que su encendido contribuyera a ubicar su posición en el mapa interactivo al cual se hizo mención anteriormente. La cantidad de personas que presenciaron este show en el mundo fue tan grande que el suceso fue reportado en varias notas de distintos sitios de internet, como por ejemplo "BTS vende 20 millones de dólares para un concierto online" publicada en Música News (2020) o "BTS atrae a más de 750.000 espectadores simultáneos al concierto en línea, 'Bang Bang Con: The Live '", que se encuentra en el sitio en español de Soompi (2020).

De nueva cuenta es importante recordar que las compañías que manejan a los artistas coreanos saben muy bien cómo atestar golpes mediáticos que dan resultados tangibles entre sus bases de fans. Tal sería el caso de Super Junior, pues en el año 2018 la banda lanzaría un par de canciones originales y un cover especialmente enfocadas en su público latinoamericano. Con la colaboración de la artista estadounidense con raíces dominicanas Leslie Grace, la banda estrenó su sencillo "Lo siento", el cual se posición rápidamente dentro del gusto del público. Algunas semanas después, la agrupación lanzaría el tema Otra vez, ahora con la participación de la banda de rock-pop mexicana Reik. Es preciso apuntar que las estrofas de las composiciones musicales hasta aquí señaladas fueron escritas e interpretadas en inglés, coreano y español, aunque hay que decir también que existen versiones de estas coplas que fueron grabadas y presentadas omitiendo las partes en español. Finalmente, Super Junior realizó el cover de la canción "Ahora te puedes marchar" que hiciera famosa el cantante nacido en Puerto Rico pero nacionalizado mexicano Luis Miguel en los años ochenta. La coreografía que se observa en el videoclip de esta pieza es una réplica casi idéntica del video original de la misma, además de que la banda interpretó el tema totalmente en español, hecho que es de destacar y que ilustraría, de buena forma, ese compromiso que también demuestran de vez en cuando los artistas con los fans. De igual manera el canal de televisión por cable mexicano Telehit -que hasta hace poco se especializaba únicamente en la proyección de videos musicales y programas de una variedad de contenido musical-, que año con año organiza un concierto masivo para conmemorar su aniversario, tuvo la atinada decisión de incluir, en el mismo año 2018, a Super Junior como una de las bandas estelares que se presentaría en el Estadio Azteca con el motivo del cumpleaños número 25 de dicha emisora. Al parecer, el hecho de haber contemplado a una banda de K-pop para casi protagonizar un evento tan grande no había sucedido con anterioridad, aunque Telehit ya empezaba a probar con algunos programas que presentaban el K-pop como parte de sus contenidos. Aparentemente esta estrategia le ha dado resultados fructíferos a este canal de televisión, posiblemente debido a que en México existen al día de hoy varias Fanpages en Facebook de grupos de K-pop, entre las que es posible encontrar: BTS México Alianza Latina con 218.761 likes y 244.692 followers; GOT7 México 76.835 likes y 78.269 followers; BlackPink México 63.448 me gusta y 66.483 seguidores; EXO Planet México con 52.134 likes y 52.359 followers; Twice México con 49.484 me gusta y 54.145 seguidores; Monsta X México con 46.937 likes y 48.758 followers; NCT 37.758 me gusta y 38.803 seguidores; ELF Support Mx con 24.104 likes y 25.707 followers. 


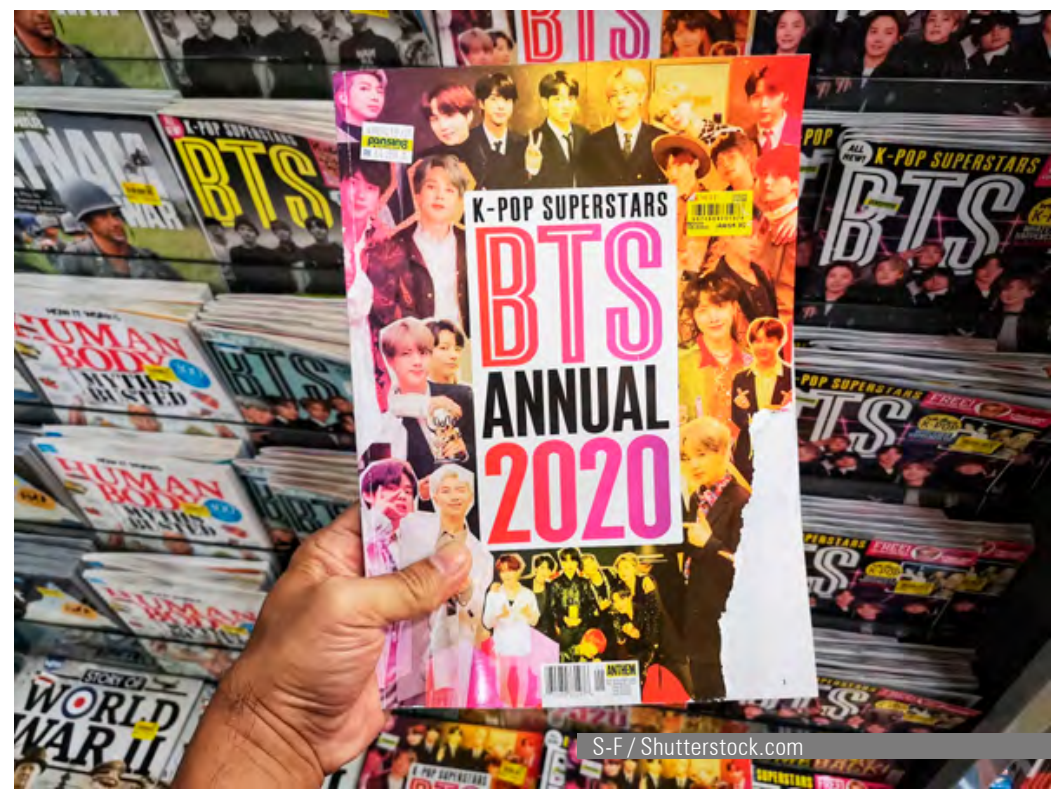

Aunado a lo anterior, en Ciudad de México se han llevado a cabo eventos relacionados con el Hallyu impulsados por los propios fans, cumpliendo con una de las características del Hallyu 2.0 a la que Mauro Neves (2018) se refiere como la producción de contenido coreano fuera de Corea del Sur. A modo de ejemplo, el fandom E.L.F de México organizó un proyecto cultural para conmemorar la visita de Super Junior al país en el año 2018, así como el décimo tercer aniversario de la agrupación. Para esto, el grupo de fans llevó a cabo una exposición de distintas fotografías de la banda y sus integrantes en conciertos que se realizaron previamente en México. Estas imágenes fueron colocadas en una estación del sistema de transporte colectivo metro en la capital mexicana y el embajador de Corea del Sur se dio el tiempo necesario para asistir a la inauguración de la muestra. El gesto al parecer fue bien recibido por la banda, que incluso se posicionó al respecto agradeciendo este esfuerzo a sus fans mexicanos a través de sus redes sociales oficiales. En este mismo tenor, hasta el mes de septiembre del año 2020 se habían celebrado ya dos ediciones de la exhibición K-pop: fenómeno global coreano presentado en el Museo Nacional de las Culturas del Mundo en la Ciudad de México. Esta iniciativa partió de la organización de distintos miembros de fandoms en México con el fin de exponer al público más de 400 artículos entre discos, lighsticks oficiales, cromos y coleccionables de diferentes grupos de K-pop de 1996 a 2019, según un reporte elaborado y publicado por el diario Milenio (2020). Todos los artículos exhibidos pertenecen a los ya mencionados miembros de diferentes fandoms en México, quienes prestaron sus adquisiciones para su exhibición. Aunque es un hecho que el público del K-pop no es una comunidad homogénea -pues no todos los fandoms apoyan ni gustan de las mismas bandas e incluso existen rivalidades entre estos-, hubo una organización y colaboración en conjunto para que el evento llevado a cabo en el Museo Nacional de las Culturas del Mundo fuera posible, gracias al conglomerado de fan clubs 'K-Fan Unión México', que curiosamente estuvo dirigido por E.L.F Support Mx. De la misma forma, vale la pena subrayar que en este mismo recinto cultural se han presentado eventos dirigidos por el Círculo Mexicano de Estudios Coreanos, una organización dedicada a fomentar, promover y difundir los conocimientos sobre la península coreana, según se aprecia en su página oficial en Facebook (@CMEC.edu). Por último, en el 
contexto mexicano se cuenta con la presencia del proyecto Mitología en el S.XXI de la Universidad Nacional Autónoma de México, colectivo que también se ha encargado de presentar charlas y conferencias sobre el tema del Hallyu y el K-pop en algunas instituciones académicas de este país.

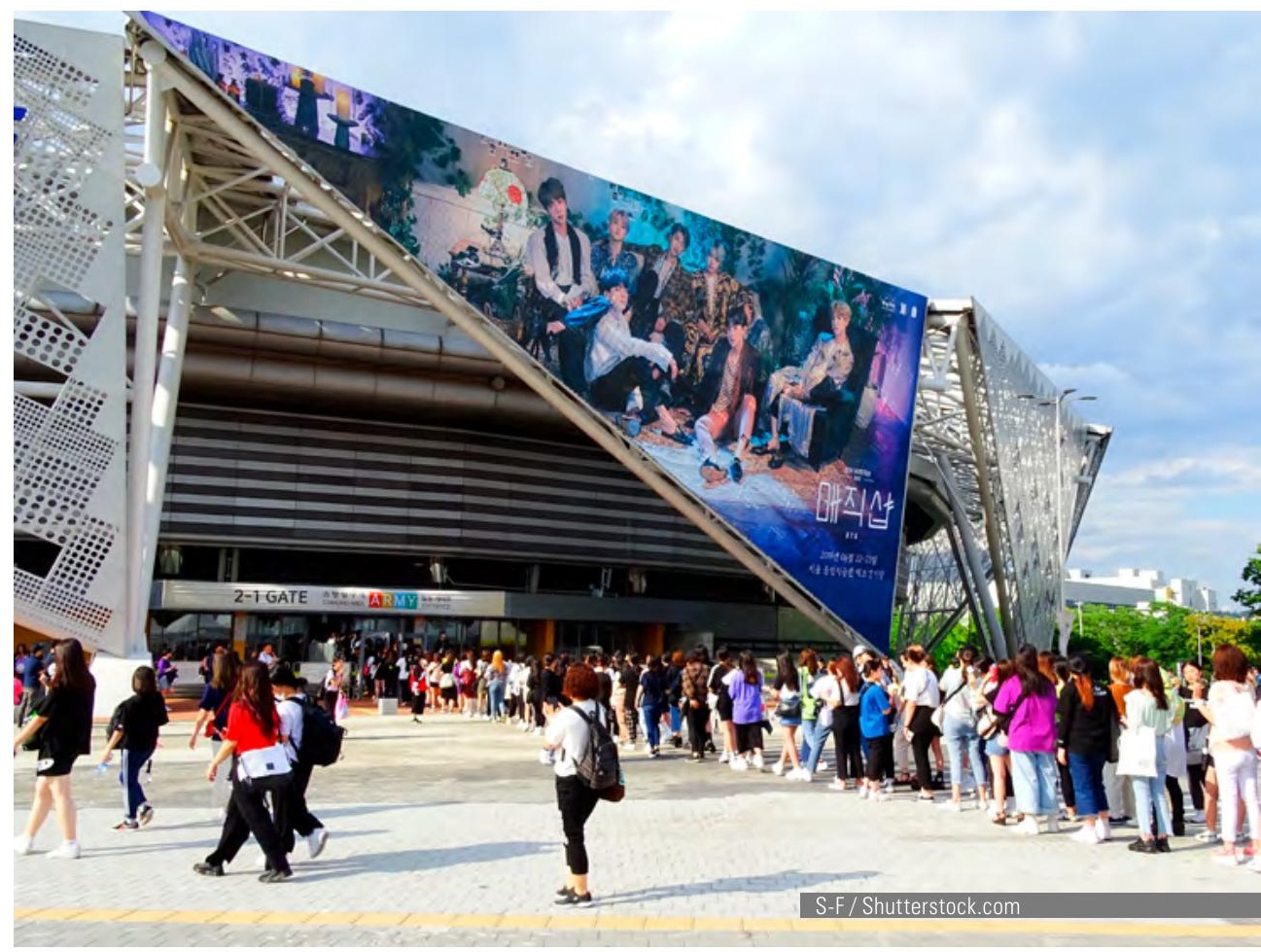

\section{A modo de conclusión}

La recopilación de algunos de los esfuerzos realizados por los fans y sus grupos de fandoms que se ha presentado hasta aquí, encuentra relación con lo que Langdon Winner (2004) denomina "comunidades de interés". Para el teórico político estadounidense estas comunidades están conformadas por individuos con gustos y puntos de vista similares, pues "gracias al internet los usuarios tienen las herramientas suficientes que les permiten delimitar aquella serie de asuntos que se centran justamente en lo que les interesa en un momento dado" (Winner, 2004, pp. 62-63). Al respecto, los fans de las distintas manifestaciones culturales contenidas en el Hallyu buscan aprovechar los recursos que están a su alcance para lograr acercarse cada vez más a sus objetivos mediante estrategias diversas que implican la creatividad y la colaboración como elementos de suma relevancia. Entendiendo, quizá, que hoy en día las formas de comunicación provienen de distintos orígenes y que la innovación juega un papel determinante, ya que el universo digital aparece como parte fundamental de la vida cotidiana de la mayoría de las personas.

De manera que las distintas manifestaciones de la Ola Coreana, vistas como productos culturales derivados de una gran industria cultural, "generan formas de percepción y son parte de un proceso de construcción de significados" (Guillén, 2013, p. 18). Además, tienen la capacidad de conformar o configurar -modelar-, dar forma -moldear-y cambiar -modificar- percepciones y conductas de los individuos que los consumen, pero no solo de ellos, pues todos los actores involucrados en los procesos de producción, diseño, circulación y distribución de la industria -Hallyu- desempeñan un papel de 
suma trascendencia (Díaz, 2020 en Alpízar, 2020). Un punto medular resultante de las industrias culturales descansa en las estrategias de significación de las manifestaciones culturales y el deseo que estas producen en los fans, en este caso. Esta idea se aproxima velozmente a la percepción del consumo que sostiene García Canclini y que es un ejercicio vital para la continuidad de la Ola Coreana. De acuerdo con el antropólogo y filósofo argentino, es prudente entender el estudio del consumo más allá de su dimensión económica, y percibirlo como:

el conocimiento de las operaciones con que los usuarios seleccionan y combinan los productos y los mensajes. Siguiendo con Michel de Certeau: cómo los consumidores mezclan las estrategias de quienes fabrican y comercian los bienes, con las tácticas necesarias para adaptarlos a la vida cotidiana (García Canclini, 1999, p. 35).

Esta idea de consumo le brinda la posibilidad a esta propuesta de observar las relaciones de comunicación, y por ende de integración, colaboración y hasta de diferenciación que surgen entre las personas -fans- que componen las distintas audiencias que consumen manifestaciones culturales provenientes del Hallyu, tal cual se pudo apreciar en los ejemplos del fangagement.

Si bien es una tarea pendiente ahondar en el contenido de estos significados y la interpretación que se hace de ellos -cuestión sumamente interesante dado que las manifestaciones de la Ola Coreana intentan poner a la vista y acentuar los puntos e ideales más favorables y valorados de la sociedad y la cultura coreana- por parte de los fans, parece suficiente por ahora mostrar los ejemplos antes descritos para dar un recorrido por el viaje que han hecho los productos culturales coreanos más allá del continente asiático.

Como se observó a lo largo de este texto, la revolución digital está ocasionando una serie de cambios continuos y hasta trascendentales en la disminución de los costos en procesos de creación, producción, promoción y distribución en distintos campos, dentro de los cuales se encuentra el de la cultura, cuestión evidente en el caso de la Ola Coreana. La parte más importante de la industria creativa digital Hallyu radica en las nuevas técnicas empleadas para difundir mensajes a mayor escala, ${ }^{9}$ pues la evolución de las redes sociodigitales y su influencia en el ámbito de los productos y las manifestaciones culturales que en un principio se presentaban solo en ámbitos locales, ha permitido que los fanáticos de todo el mundo, incluidos los de América Latina, accedan en gran medida a las redes sociodigitales para desde ahí disfrutar de los K-dramas, del K-pop, de películas y de 'creadores de contenido' que les muestran productos de belleza y cuidado personal, la gastronomía y otra serie de manifestaciones culturales provenientes de Corea del Sur (Lee \& Nornes, 2015; Jin, 2016; Dal Yong \& Tae-Jin, 2017), dejando claro que una de las principales funciones -si no es la principal- de los productos culturales de ahora es la de entretener. Pese a que las audiencias reunidas alrededor del Hallyu no siempre son homogéneas, existe una gran gama de grupos de fans o fandoms que se organizan y trabajan comprometidamente en favor de sus propias causas, reproduciendo globalmente-quizá de forma inconsciente- la cultura dominante de la Olea Coreana a través de las distintas estrategias -caracterizadas por la creatividad y la colaboración- que estos fandoms aplican y que en el fondo, persiguen un mismo fin: continuar trabajando conjunta y comprometidamente en favor de una de las manifestaciones más redituables y mejor posicionadas del Hallyu que ha trascendido fronteras: el K-pop.

9 El fundador y productor de SM Entertainment, Lee, Soo-Man, consciente de esta situación, definió la estrategia de difusión utilizada por su empresa como "tecnología cultural" (The Korean Wave, 2011, p. 70; Gunjoo Jang y Won K. Paik, 2012, p. 199) 


\section{Referencias}

- Alpízar, R. (2020). La industria cultural pornográfica digital: Las modelos de cámara web del sitio My Free Cams.com. Tesina de maestría, UAM Iztapalapa: México.

- $\quad$ Anguita, C. (14 de junio de 2020). "BANGBANGCON: The Live, BTS sorprende a sus fans con un concierto online". Recuperado de [https://thehallofstars.com/2020/06/14/bangbangcon-the-live-bts-sorprende-asus-fans-con-un-concierto-online/]

- Arriojas, C. \& Réquiz, V. (2019). “Devorando el Hallyu: Desarrollo, hibridación y canibalismo latinoamericano”. Revista Mundo Asia Pacífico. vol. 8. no. 14.

- Benjamin, W. [1935]. (2003). La obra de arte en la época de su reproductibilidad técnica. México: Editorial Itaca.

- Bijker, W. E., Hughes, T. P., \& Pinch, T. J. (Eds.). (1987). The Social Construction of Technological Systems: New Directions in the Sociology and History of Technology. The MIT Press: Cambridge, Massachusetts.

- Creative Industries Council. (2014). Create UK. Creative Industries Strategy, Opal Print, Reino Unido, [en línea https://bit.ly/1m0g4M0]

- Cremayer, L. (2020). De los Mass Media a los K-Media del Hallyu. Trabajo presentado en el seminario permanente "Japón y los imaginarios transculturales: Asia, diálogos y resonancias en la globalidad".

- Díaz Cruz, R. \& Roque de Castro, R. (2014). "Reflexiones sobre la construcción del ecosistema doméstico de la tecnología Modalidades de apropiación de las TIC desde la desigualdad". Versión. Estudios de Comunicación y Política, 34, UAM: México.

- Doobo, S. (2006). "Hybridity and the Rise of Korean Popular Culture in Asia". SAGE Journals, 1, 25-44.

- El concierto en línea 'Beyond LIVE' de Super Junior termina con éxito con cerca de 123.000 espectadores de todo el mundo". (1 de junio de 2020). Agencia de Noticias Yonhap. Recuperado de [https://sp.yna. co.kr/view/ASP20200601001900883?fbclid=IwAR3hN0xKWOgBJ7dZIGxOUdprfjIPqcUFuhmfjTOqse9x80 IA6_LcerTBfFY]

- "Expondrán la cultura detrás del K-pop en museo de la CdMx". (9 de enero de 2020), en Notimex. Recuperado de [https://www.milenio.com/cultura/K-pop-expondran-cultura-coreana-museo-cdmx]

- García Canclini, N. (1987). Políticas culturales en América Latina. México-Barcelona-Buenos Aires: Cultura y Sociedad Colección Enlace.

- ․ (1999). “El consumo cultural: una propuesta teórica”, en: Guillermo Sunkel (coord.): El Consumo Cultural en América Latina (pp. 26-49). Colombia: Convenio Andrés Bello.

- . (2002). "Las industrias Culturales y el Desarrollo de los países americanos", en Revista Interamericana de Bibliografía.

- Guevara, A. (6 de diciembre de 2019). "iBTS POP-UP: House Of BTS llega a la Ciudad de México!" en K-magazine. Recuperado de [https://www.k-magazinemx.com/bts-pop-up-house-of-bts-llega-a-la-ciudadde-mexico/]

- Guillén, H. (2013). Desnudando al porno. Controversias en torno a la comercialización del sexo a través del proceso de producción de pornografía amateur: la Editorial Matlarock en México. Tesis doctoral en Ciencias Antropológicas UAM Iztapalapa: México.

- Gutiérrez, B. (2006). "The Korean Wave Hallyu", The Seattle Times.

- "House of BTS fue un rotundo éxito en la Ciudad de México iFelicidades ARMY!". (13 de diciembre de 2019), en La Verdad. Recuperado de [https://laverdadnoticias.com/espectaculos/House-of-BTS-fue-unrotundo-exito-en-la-Ciudad-de-Mexico-Felicidades-ARMY-20191213-0255.html]

- "Inauguran la Pop-Up House de BTS en Plaza Carso". (16 de diciembre de 2019), en Publimetro. Recuperado de [https://www.publimetro.com.mx/mx/noticias/2019/12/16/publirreportaje-inauguran-la-pop-up-housebts-en-plaza-carso.html]

- Jang, G. \& Paik, Won K. (2012). "Korean Wave as Tool for Korea's New Cultural Diplomacy". Scientific Research, 3, 196-202. DOI: 10.4236/aasoci.2012.23026

- Jin, Dal Yong, \& Yoon, Tae-Jin. (2017). “The Korean Wave: Retrospect and Prospect”. International Journal of Communication, 11, 2241-2249.

- Jorquera, C. (2016). “La era de la K-Diplomacy: El Hallyu como estrategia clave del softpower coreano y su alcance en América Latina", Policy Briefs, Chile.

- Juárez Postigo, L.; Blasco López Ma F. đ Blázquez Jiménez J. A. (2015). “La marca país como factor clave del turismo: revisión de las escalas de medición". Revista Turydes: Turismo y Desarrollo, 19, diciembre 2015. ISSN: 1988-5261 [en línea http://www.eumed.net/rev/turydes/19/marca-pais.html]

- Katz, R. (2015). El ecosistema y la economía digital en América Latina, CEPAL, CAF, Fundación Telefónica.

- Kim, Bok-rae. (2015). "Past, Present and Future of Hallyu (Korean Wave)". American International Journal of Contemporay Research, 5, 154-160.

- . (2018). "History of Korean Popular Culture: From Its Embryonic Stage to Hallyu (Korean Cultural Wave)", American International Journal of Contemporay Research, 4, 13-26. doi: 10.30845/aijcr. v8n4p2 
- Korean Culture and Information Service. (2011). "The Korean Wave: A New Pop Culture Phenomenon". Contemporary Korea No. 1. Seoul.

- "Las telenovelas coreanas comienzan a atraer a un gran público". (1 de julio de 2012), en Expansión. Recuperado de [https://expansion.mx/entretenimiento/2012/07/01/las-telenovelas-coreanas-comienzana-atraer-a-un-gran-publico]

- Lee, D. (2003). Why is Winter Sonata a Big Hit in Asia? Koreafilm.org. Recuperado de [http://www. koreanfilm.org/tvdramas/wintersonata.html]

- Lee, B. (2019). "All Eyes On Seoul: A Study of The Korean Wave", Publication Version One. Independent/ Freelance Journalist, 3-26.

- Lee, J. (2010). Winter Sonata Dreams: The Influence of the Korean Wave on Japanese Society. Florida State University.

- Lee, Sue Jin. (2011). "The Korean Wave: The Seoul of Asia". The Elon Journal of Undergraduate Research in Communications, 1, 85-93.

- Mejía, P.F. (2015). Análisis del poder blando en China. Tesis de maestría. Universidad Andina Simón Bolívar Sede Ecuador.

- Mérida, J. (2015). "Venden dramas bonitos y baratos” en El Universal.mx. Recuperado de https://archivo. eluniversal.com.mx/espectaculos/2015/impreso/venden-dramas-bonitos-y-baratos-136097.html

- Molnar, V. (2013). "La ola K-pop rompe en Latinoamérica. No son chinos, son C-O-R-E-A-N-O-S". Revista Replicante, México [en línea https://revistareplicante.com/la-ola-K-pop-rompe-en-latinoamerica/].

- Morley, D. (2008). Medios, modernidad y tecnología: la geografía de lo nuevo. Gedisa.

- Neves, M. (9 de agosto de 2018) Conferencia sobre Hallyu, Centro Cultural Coreano en la Ciudad de México [audio]. Recuperado en archivo de audio propio.

- ¿Qué es y cómo se construye una marca país en Latinoamérica? (s.f.). CEUPE magazine. Recuperado de https://www.ceupe.com/blog/que-es-y-como-se-construye-una-marca-pais-en-latinoamerica.html

- Santos, M. J. (1994). "Un análisis social de la innovación tecnológica: conflicto y significados en una empresa innovadora". Estudios Sociológicos, vol. 12 no. 35, 399-419. México: El Colegio de México. ISSN-e 0185-4186

- Secretaría de Cultura. (2018). Mapa de ruta de industrias creativas digitales, (Primera edición).

- "Super Junior ya está en México". (27 de abril de 2018), en La Verdad. Recuperado de [https:// laverdadnoticias.com/espectaculos/K-pop-SUPER-JUNIOR-ya-esta-en-Mexico-20180427-0096.html]

- Thomas, H. (2008). "Estructuras cerradas vs. Procesos dinámicos: trayectorias y estilos de innovación y cambio tecnológico". en Hernán Thomas \& Alfonso Buch, (coords.): Actos, actores y artefactos (pp. $217-$ 290). Sociología de la tecnología, Bernal: Universidad de Quilmes.

- Thompson (1998) J. B. (1998). Los media y la modernidad: una teoría de los medios de comunicación. Barcelona: Paidós

- Turriza, M. (2019). "El imperio de la cultura fan. El juez del entretenimiento", en Siglo Nuevo. Recuperado de https://siglonuevo.mx/nota/1795.el-imperio-de-la-cultura-fan

- UNESCO. (2009). "Políticas para la creatividad", en Expresiones culturales. Recuperado de unesco.org

- Urteaga, M. (2012). "De jóvenes contemporáneos: Trendys, emprendedores y empresarios culturales”. En Néstor García Canclini; Francisco Cruces y Maritza Urteaga, (coords.): Jóvenes, culturas urbanas y redes digitales (pp. 26-44). México: Ariel.

- Uscanga, C. (2014). "Iniciativas de cooperación cultural de Korea Foundation en México 1994-2014", en Revista de Relaciones Internacionales de la UNAM, (127) 151-165.

- Vargas Llosa, M. (2012). La civilización del espectáculo, México: Alfaguara

- Vidal, L. A. (2014). Pop Power: Diplomacia Pop para una Sociedad Global, Perú.

- Winner, L. (2004). "Internet y los sueños de una renovación democrática". Nómadas, no. 21, 55-71. Universidad Central de Colombia.

- " "Winter Sonata' sequel to start shooting later this year". (14 de abril de 2015), en The Korea Observer. Recuperado de [http://www.koreaobserver.com/bae-yong-joon-to-make-winter-sonata-sequel-later-thisyear-28003/] 